Original Research Paper

\title{
Benthic Habitat Mapping Using Sentinel-2A Satellite Imagery in Serewe Bay
}

\author{
Denianto Yoga Sativa ${ }^{1 *}$, I Gede Nano Septian ${ }^{1}$ \& Febrian Kusuma Atmanegara ${ }^{1}$ \\ ${ }^{1}$ Program Studi Pemanfaatan Sumberdaya Perikanan, Fakultas Perikanan, Universitas 45 Mataram, \\ Indonesia
}

\author{
Article History \\ Received : November $26^{\text {th }}, 2021$ \\ Revised : December $16^{\text {th }}, 2021$ \\ Accepted : December $26^{\text {th }}, 2021$ \\ Published : January $05^{\text {th }}, 2022$ \\ *Corresponding Author: \\ Denianto Yoga Sativa, \\ Program Studi Pemanfaatan \\ Sumberdaya Perikanan, Fakultas \\ Perikanan, Universitas 45 \\ Mataram, Indonesia \\ Email: \\ denianto.u45mataram@gmail.com
}

\begin{abstract}
Serewe Bay is an important area for sustainable fisheries. This information on benthic habitats is important to know for sustainable management. However, at the moment there is no information on the distribution of benthic habitats in Serewe Bay. The research utilizes Sentinel 2A satellite imagery where the image used is obtained through the earthexplorer.usgs.gov website. Image data will be analyzed through several correction analysis processes, namely reflectance correction, sunglint, and water column or Lyzenga in order to obtain an image display that can be used to identify benthic habitats in Serewe Bay. In addition, a field data survey was also carried out to test the accuracy of the results of processing the Sentinel 2A satellite image of Serewe Bay. Image processing results show that there are 3 categories of benthic habitats, namely Seagrass, Sand and Mixed habitats in which there are macroalgae, dead coral, and coral fractures. The results of the field survey and accuracy calculations show that the accuracy of sentinel 2A image processing in Serewe Bay reaches $63.41 \%$ with the dominant benthic distribution consisting of seagrass, mixed benthic habitat and sand. Meanwhile, the calculation of the area of important benthic habitats such as seagrass beds in Serewe Bay can reach $156 \mathrm{Ha}$.
\end{abstract}

Keywords: Mapping, Benthic, Sentinel, Serewe Bay

\section{Pendahuluan}

Habitat bentik merupakan tempat hidup dari berbagai jenis organisme yang tersusun oleh berbagai komunitas biotik dan abiotik seperti rumput laut, lamun, alga, karang hidup, karang mati dengan tipe substrat seperti pecahan karang, lumpur, dan pasir (Anggoro, 2015; Zhang et al., 2013). Habitat bentik khususnya Terumbu karang dan lamun merupakan ekosistem yang memiliki nilai penting bagi manusia baik hal ekonomi dan jasa lingkungan yang ditimbulkan oleh habitat bentik tersebut. Prawoto dan Hartono (2018) menjelaskan bahwa ekosistem terumbu karang dan lamun merupakan komponen penyusun yang sangat penting yang memeriliki peran vital seperti tempat pemijahan, mencari makan, tempat tinggal biota laut, pelindung pantai dari gelombang, stabilisator sedimen, penjernih perairan, penyerap karbon, sumber material industri dan farmasi, serta pariwisata. Namun demikian, peran tersebut tidak menjadikan terumbu karang bebas ancaman, (Hoegh-Guldberg, et al. 2007) dan (Pandolfi et al. 2003) bahkan menjelaskan bahwa terumbu karang di dunia saat ini mengalami ancaman dari sejumlah masalah lingkungan serta tekanan antropogenik, seperti yang terjadi di samudra Hindia yang 20\% karangnya telah rusak dan khususnya di Indonesia, UNEP (1988) dan Hadi et al. (2018) melaporkan bahwa terumbu karang dengan kategori baik hanya mencapai $22.96 \%$.

Kondisi habitat bentik penting yang secara umum sangat rawan memutuhkan perlindungan yang mana salah satunya melalui proses monitoring habitat bentik khususnya melalui sebaran spatial dan temporal dengan memanfaatkan citra satelit. Penggunaan citra satelit dalam mengetahui sebaran habitat bentik terumbu karang memiliki kelebihan yaitu dapat menganalisis obyek dalam skala luas dengan tingkat efektifitas penggunaan biaya yang paling baik dibandingkan dengan metode lainnya (Mumby, et al. 1999). Seperti diketahui terdapat 
beberapa jenis citra satelit yang potensial untuk dapat digunakan seperti ALOS, SPOT, WORLDVIEW, LANDSAT, SENTINEL, dan lain-lain. Namun demikian, salah satu citra satelit yang memiliki keunggulan resolusi yang baik serta tidak berbayar adalah satelit sentinel. Citra Sentinel memiliki keunggulan yang tidak berbayar (open source) dan memiliki resolusi spatial yang mencapai 10 meter. Selain itu Sentinel-2 memiliki performa yang baik dalam memonitoring habitat bentik secara saintifik, dan melalui resolusi spasial yang mencapai $10 \mathrm{~m}$ merupakan kunci dalam mendeliniasi fitur-fitur bentik penting seperti terumbu karang dan lamun (Hedley, et al, 2016 dan Hedley, et al. 2018).

Teluk Serewe merupakan salah bagian perairan Provinsi Nusa tenggara Barat yang masuk ke dalam zona budidaya berkelanjutan dimana hal tersebut tertuang di dalam Rencana Zonasi Wilayah Pesisir dan Pulau-Pulau Kecil NTB tahun 20172037. Hingga saat ini, Teluk Serewe dikenal sebagai salah satu sentra perairan penghasil Rumpu laut terbesar di Pulau Lombok. Praktik budidaya dan perikanan yang ada di Teluk Serewe dapat menimbulkan dampak negatif bagi habitat bentik di perairan khususnya Terumbu Karang dan Lamun. Peran penting Teluk serewe sebagai kawasan budidaya tidak di dukung dengan informasi sebaran habitat bentik di Teluk Serewe. Oleh karena itu dibutuhkan penelitian terkait sebaran habitat bentik di Teluk Serewe guna mengetahui tipe habitat bentik yang tersebar di Teluk Serewe. Informasi terkait sebaran habitat bentik dapat menjadi informasi penting di dalam upaya pengembangan serta rehabilitasi kawasan di Teluk Serewe.

\section{Bahan dan Metode}

\section{Lokasi dan Data Citra}

Lokasi penelitian dilakukan di perairan Serewe, Lombok Timur, Provinsi Nusa Tenggara dan dilakukan pada bulan Januari -November 2021 (Gambar 2) dan Data citra yang digunakan dalam penelitian ini ialah Citra Sentinel-2A Multi Spectral Instrument (MSI) perekaman tanggal 21 Juni 2021 dengan kode scene L1C_T50LMR_A031317_20210621T023511.

Citra Sentinal 2A memiliki 12 band dan saluran yang mana di dalam penelitian ini hanya menggunakan 5 band yaitu band 1 (aerosol), band
2 (blue), band 3 (green), band 4 (red), dan band 8 (NIR).

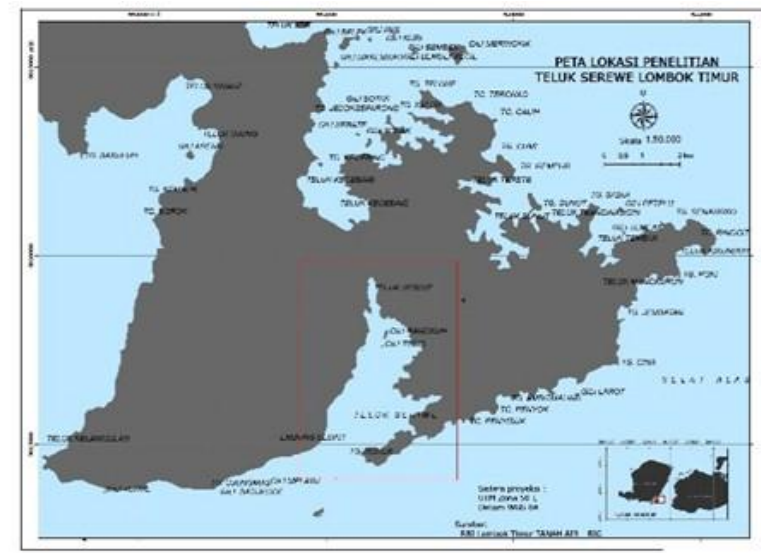

Gambar 1. Peta Lokasi Teluk Serewe, Lombok Timur

\section{Pengolahan Citra Satelit}

\section{Koreksi Reflektan}

Proses koreksi reflektan citra sentinel dilakukan melalui metode koreksi Dark Object Substraction (DOS). Proses koreksi reflektan mengkonversi nilai digital (DN) menjadi nilai energi. Proses selanjutnya, dari hasil koreksi reflektan diambil empat band yaitu band 2 (biru), band 3 (merah), band 4 (hijau), dan band 8 (inframerah dekat) untuk penggabungan layer yang dilakukan masih memanfaatkan QGIS.

\section{Koreksi Sunglint atau Riak Air}

Koreksi sunglint atau koreksi Riak Air mengikuti rumus algoritma yang dikembangkan oleh (Hochberg, et al. 2003) dan disempurnakan oleh (Hedley, 2005) yaitu

$$
\begin{aligned}
& L_{i}(V I S)^{\prime}=L_{i}(V I S)-b_{i}\left(L(N I R)-L_{\min }(N I R)\right) \\
& \text { Keterangan: } \\
& \mathrm{L}_{\mathrm{i}}(\mathrm{VIS})^{\prime}=\text { Band Visible yang telah } \\
& \begin{aligned}
\text { dikoreksi sunglint } & \\
\mathrm{L}_{\mathrm{i}}(\mathrm{VIS}) & =\text { Band Visible } \\
\mathrm{b}_{\mathrm{i}} & =\text { regression slope } \\
\mathrm{L}(\mathrm{NIR}) & =\text { Band NIR } \\
\mathrm{L}_{\min }(\mathrm{NIR}) & =\text { Nilai minimum AoI band NIR }
\end{aligned}
\end{aligned}
$$

Secar praktis, Algoritma tersebut diperoleh melalui perhitungan Region of Interest (ROI) pada Scene Citra sentinel yang kemudian nilai piksel ROI ditransformasikan menjadi algoritma Sunglint.

\section{Koreksi Kolom Air}

Koreksi kolom air di lakukan setelah pross koreksi sunglint dimana pada koreksi Kolom air 
dilakukan melalui 2 tahap yaitu a) proses masking, dan b) koreksi kolom air Lyzenga. Proses masking citra dilakukan dengan metode SPEAR Water depth pada perangkat lunak ENVI 5.1. Selanjutnya koreksi dilakukan dengan menggunakan transformasi Lyzenga (Lyzenga, 1978) dengan persamaan sebagai berikut:

$$
D I I=\operatorname{Ln}\left(R B_{i}\right)-\left(\left(k i / k_{j}\right) x \operatorname{Ln}\left(R B_{j}\right)\right)
$$

Keterangan :

DII = Invarian indeks kedalaman bawah air (Lyzenga)

$\mathrm{RBi}=$ Band dengan panjang gelombang pendek (Attenuasi air rendah)

$\mathrm{RBj} \quad=$ Band dengan panjang gelombang lebih panjang (Attenuasi air lebih tinggi) $\mathrm{ki} / \mathrm{kj}=$ Rasio koefisien attenuasi saluran yang dibandingkan

бi = ragam atau varian band $I$ (saluran dengan panjang gelombang lebih pendek)

$\sigma \mathrm{j} \quad=$ ragam atau varian band $j$ (saluran dengan panjang gelombang lebih panjang)

бij = peragam atau covarian band $i$ dan $j$

$\mathrm{ki} / \mathrm{kj}$ diperoleh dengan rumus :

$$
\begin{gathered}
k i / k j=a-\sqrt{\left(a^{2}+1\right)} \text { s ementara } a= \\
\frac{\sigma i-\sigma j}{2 x \sigma i j}
\end{gathered}
$$

Pada koreksi Kolom air, Algoritma diperoleh melalui perhitungan Region of Interest (ROI) pada Scene Citra sentinel yang kemudian nilai piksel ROI ditransformasikan menjadi algoritma Kolom air.

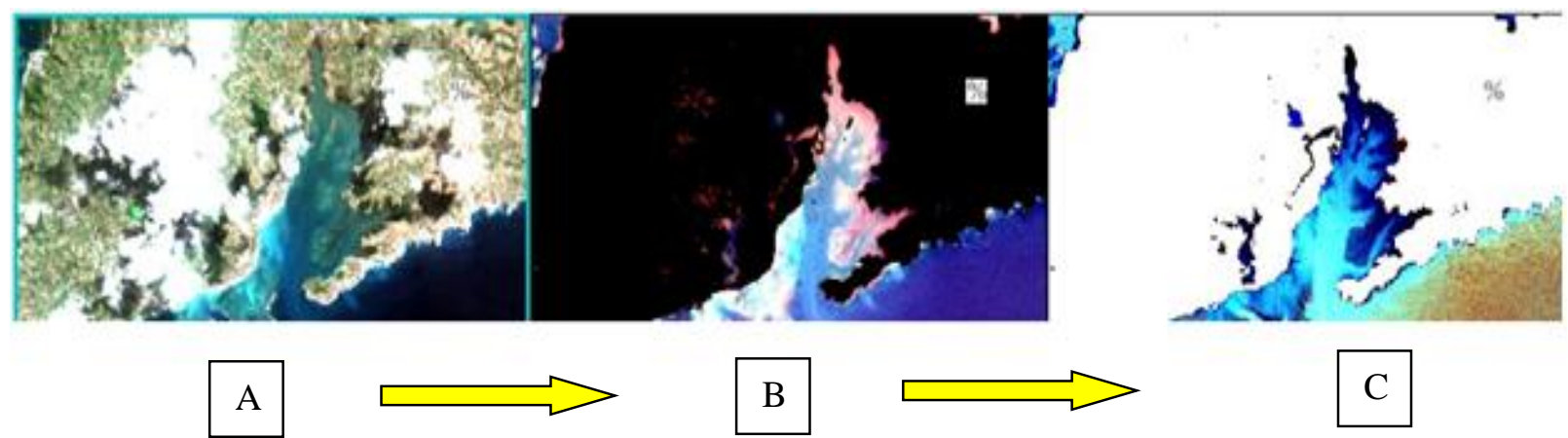

Gambar 2. Proses koreksi Citra, 2A). Koreksi reflektan 2B). Koreksi sunglint 2C). Koreksi kolom air

\section{Klasifikasi Unsupervised}

Hasil pengolahan koreksi Kolom air kemudian dilakukan klusterisasi pixsel melalui metode klasifikasi multispektral tak terselia (unsupervised classification) ISODATA dan akan menghasilkan 4 kelas yang akan di validasi dan di uji akurasinya yaitu karang, lamun Pasir dan Campuran (Patahan karang dan Terumbu Mati).

\section{Pengolahan Hasil Lapangan}

Survei lapang pada penelitian dilakukan untuk mendapatkan informasi jenis objek habitat bentik yang mana metode yang digunakan ialah metode stop and go dalam pengambilan informasi pada titik sampel habitat bentik. Hasil survey akan digunakan untuk uji akurasi dengan cara memilih seluruh titik survei untuk melihat keakuratan citra Sentinel 2.

\section{Uji Akurasi}

Uji akurasi klasifikasi dilakukan untuk menguji tingkat akurasi peta yang dihasilkan antara klasifikasi digital dengan sampel uji dari hasil kegiatan lapangan. Uji akurasi dilakukan dengan confusion matrix (Lewis \& Brown, 2001) yaitu :

Overall accuracy $\quad=\frac{n j j}{n+j}$

Producer accuracy $\quad=\frac{n i i}{n i+k}$

User accuracy

$$
=\frac{\sum_{i=1}^{k} n j j}{n}
$$

Kappa coefficient $\quad=\frac{\sum_{i=1}^{k} n i i-\sum_{i=1}^{k} n i+n i+i}{n^{2}-\sum_{i=1}^{k} n i+n i+i}$

Keterangan :

$k=$ jumlah baris pada matriks

$n \quad=$ jumlah pengamatan

nii $\quad=$ jumlah pengamatan pada

kolom ke-i dan baris ke-i

$n j j=$ jumlah pengamatan pada

kolom ke-j dan baris ke-j 


$$
\begin{array}{ll}
n i+k & =\text { total marginal baris ke-I } \\
n+j & =\text { total kolom } .
\end{array}
$$

\section{Hasil dan Pembahasan}

\section{Koreksi Sunglint}

Proses pengolahan citra Sentinel 2A dimulai dengan koreksi citra dengan melakukan dua proses utama yaitu koreksi sunglint dan water column correction (DII) yang mana hasil proses kedua koreksi tersebut ditunjukkan pada Gambar 2. Kedua proses koreksi tersebut tersebut mengubah visualisasi citra dari citra aslinya menjadi citra sunglint atau riak air dan akhirnya menjadi citra DII.

Tabel 1. Formula koreksi sunglint

\begin{tabular}{lcc}
\hline Visible band & Formula glint & $\mathrm{R}^{2}$ \\
\hline B2 BLUE & B2-(1.3343*(B5-101)) & 0,7718 \\
B3 GREEN & B3-(1.3227*(B5-101)) & 0,8525 \\
B4 RED & B4-(1.0956*(B5-112)) & 0,8841 \\
\hline
\end{tabular}

Penerapan koreksi sunglint dilakukan untuk mengurangi efek tidak rata yang disebabkan oleh adanya arus dan gelombang yang mana hal demikian mengakibatkan ketidakjelasan pembacaan informasi dibawah kolom air perairan. Gambar 2B merupakan hasil koreksi Sunglint yang mana diperoleh melalui penerapan algoritma (Tabel 1) Sunglint. Nilai koefisien determinasi $\left(\mathrm{R}^{2}\right)$ yang memiliki nilai mendekati 1 menggambarkan formula yang dibangun akan dapat menghilangkan efek sunglint dengan baik.

\section{Koreksi Kolom Air}

Koreksi kolom air ialah proses koreksi yang dilakukan setelah koreksi Sunglint. Tampilan citra melalaui koreksi Kolom air (Gambar 2C) diperoleh melalui penerapan formula Kolom air atau DII (Tabel 2). Koreksi kolom bertujuan untuk menghilangkan efek dari suatu kolom air yang mempengaruhi terhadap nilai pantulan suatu objek yang diterima sensor dengan memperhatikan nilai dari band biru dan band hijau dari citra yang digunakan (Purwanto et al. 2020). Sementara itu, Prayudha (2014) menerangkan bahwa informasi dasar laut dapat ditentukan dari perhitungan nilai koefisien atenuasi (pelemahan) kolom air antara saluran i dan $\mathrm{j}(\mathrm{ki} / \mathrm{kj})$.

Tabel 2. Algoritma Koreksi Kolom Air

\begin{tabular}{cccc}
\hline & Covar & $\mathrm{a}$ & $\mathrm{Ki} / \mathrm{kj}$ \\
\hline B1B2 & 0.0772 & -0.087 & 0.9168 \\
B1B3 & 0.0585 & -1.086 & 0.3902 \\
B2B3 & 0.0913 & -0.623 & 0.5555
\end{tabular}

Hasil pengolahan pada koreksi kolom air memperlihatkan perubahan citra dari citra hasil koreksi sunglint menjadi citra koreksi kolom air yang memperlihatkan perbedaan kedalaman dan pola habitat bentik yang ada di pesisir di teluk serewe. Hasil citra yang telah dikoreksi melalui metode koreksi kolom air menghasilkan gambar yang tampak lebih gelap yang mana hal ini disebabkan oleh efek pantulan cahaya saat mengenai objek yang sama pada kedelaman yang berbeda. Seperti yang dijelaskan oleh Prawoto dan Hartono (2018) bahwa pasir yang berada pada perairan yang lebih dalam akan cenderung memiliki warna lebih kebiruan dibandingkan dengan pasir yang terletak di perairan yang lebih dangkal. Selain itu, adanya pengurangan intensitas cahaya akibat adanya peningkatan kedalaman (atenuasi) diduga menjadi penyebab terjadinya hal tersebut.

\section{Klasifikasi unsupervised}

Habitat bentik diklasifikasikan dengan menggunakan metode unsupervised melalui Isodata classifications pada perangkat lunak ENVI. Pengklasifikasian hasil pengolahan citra dilakukan dengan tidak terbimbing atau unsupervised dimana interpretasi klasifikasi habitat bentik terumbu karang, lamun, pasir dan habitat campuran ditentukan secara visual dengan melihat mengelompokkan warna, rona, tekstur, dan pola. Berdasarkan hasil klasifikasi dihasilkan hanya tiga tipe klasifikasi yaitu lamun, pasir dan habitat campuran. Klasifikasi tersebut serupa dengan interpretasi yang dilakukan oleh Sari et al. (2020) yang menemukan karakter kelas lamun yang memiliki warna dan rona yang Gelap, tekstur halus, dengan pola cenderung parallel dan terletak di rataan terumbu dan kelas pasir yang memiliki warna cenderung cerah dengan pola acak dan terletak di zona rataan terumbu. 


\section{Akurasi dan Pengumpulan Sampel Lapangan}

Pengambilan sampel habitat bentik dilakukan untuk memastikan kebenaran hasil klasifikasi yang diperoleh dari hasil analisa citra sentinel. Sampel yang diambil berjumlah 39 titik sampel yang terdiri atas 18 titik lamun, 10 titik pasir dan dan 11 titik habitat campuran. Ketiadaan sampel terumbu karang dalam pengambilan titik sampel karena ketiadaan kemunculan klasifikasi terumbu karang pada hasil klasifikasi unsupervised. Berdasarkan hasil analisis pengujian akurasi hasil pengeolahan citra diketahuibahwa nilai akurasi keseluruhan mencapai $63.41 \%$ dengan kappa sebesar 0.4128 (Tabel 3). Hasil tersebut dapat dikatakan hasil akurasi yang cukup baik karena berdasarkan SNI 7716:2011 yang menyebutkan bahwa untuk pemetaan habitat dasar perairan dangkal tingkat akurasi harus mencapai nilai minimal 60\% (BIG 2014). Dengan demikian nilai akurasi keseluruhan mengindikasikan hasil pengolahan citra sudah diatas batas minimal akurasi yang dipersyaratkan dan tentunya hasil sebaran habitat bentik dapat diterima (Tabel 3). Hasil akurasi yang mencapai $63.41 \%$ memiliki nilai yang lebih tinggi dibeberapa penelitian dengan metode serupa seperti yang dilaporkan oleh Sari et al. (2020) mendapati tingkat akurasi mencapai $60.78 \%$. Sementara itu, terdapat pula penelitian yang menunjukkan nilai akurasi yang lebih tinggi dibandingkan penelitian ini, seperti yang dijelaskan oleh Hafizt et al. (2017) dan Prawoto dan Hartono (2018) yang mendapati nilai akurasi berturut-turut $83.93 \%$ dan $80.73 \%$. Hafizt et al. (2017) menjelaskan bahwa tinggi rendahnya nilai akurasi peta dapat disebabkan oleh distribusi sampel yang kurang merata pada saat pengambilan sampel (Hafizt et al. 2017).

Tabel 3. Uji Akurasi Citra Sentinel Teluk Serewe

\begin{tabular}{ccccc}
\hline & Lamun & Pasir & Mix & \\
\hline Lamun & 7 & 0 & 1 & 8 \\
Pasir & 9 & 6 & 0 & 15 \\
Mix & 3 & 2 & 13 & 18 \\
& 10 & 8 & 14 & 41 \\
& Overall Accuracy $=63.41 \%$ & \\
& Kappa Coefficient $=0.512$ & \\
\hline
\end{tabular}

\section{Sebaran Habitat Bentik}

Habitat Bentik, khususnya terumbu karang dan lamun merupakan dua ekosistem penting di dalam mendukung kehidupan ekosistem laut. Ditambah lagi terumbu karang merupakan ekosistem penting yang seringkali menjadi obyek wisata yang seringkali dicari oleh para wisatawan. Berdasarkan hasil analisa dan survey lapang lokasi terkait persebaran habitat bentik dengan menggunakan Citra Sentinel 2A menunjukkan bahwa ekosistem lamun tersebar di Teluk Serewe (Gambar 3) dengan persebaran lamun dominan pada pada bagian timur teluk Serewe. Sementara itu, hasil analisa piksel citra satelit tidak tidak menunjukkan adanya ekosistem terumbu karang yang baik di Teluk Serewe. Ketiadaan ekosistem terumbu karang yang dimaksud adalah terumbu karang tidak dapat diklasifikasikan berbasis piksel namun berdasarkan hasil lapangan beberapa koloni karang tersebar secara acak di kelas lamun dan campuran. Kesulitan didalam klasifikasi sebaran karang dikarenakan tidak adanya batas yang jelas dari terumbu karang sehingga di lapangan sebaran acak koloni kecil karang masuk masuk ke dalam kelas lamun dan juga kelas campuran. Hal demikian seperti yang ditemukan oleh Hafizt et al. (2017) yang menemukan kelas campuran yang didalamnya ditemukan karang keras, makroalga, Patahan karang dan batu. Hafizt dan Danoedoro (2015) menambahkan bahwa objek terumbu karang dan padang lamun cukup sulit diklasifikasikan berbasis piksel secara langsung, sehingga dibutuhkan batasan zona habitat (zona habitat lamun, zona habitat terumbu karang, dan zona campuran) agar hasil klasifikasi antara kedua objek tersebut lebih baik.

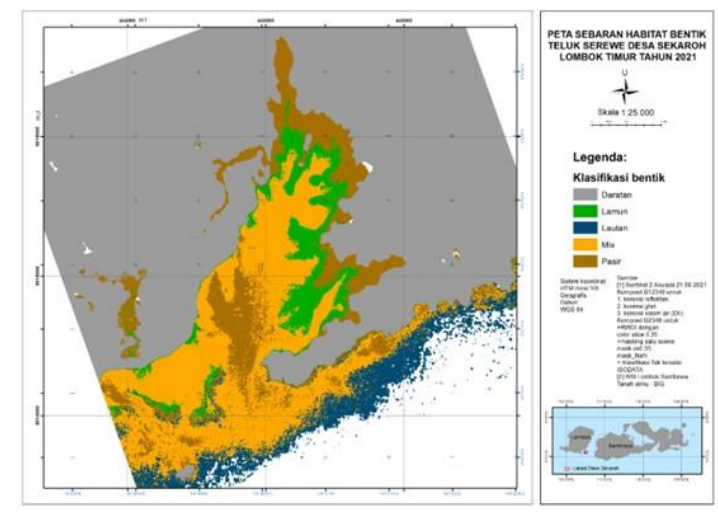

Gambar 3. Peta Sebaran Lamun di Teluk Serewe 
Analisis Luasan habitat bentik menunjukkan bahwa total luas lamun mencapai $156 \mathrm{Ha}$ dengan lokasi lamun terluas berada di lokasi timur Teluk Serewe. Sementara itu, Kelas Campuran memiliki luasan 601,2 Ha dan Kelas Pasir memiliki luasan 337.5 Ha. Teluk Serewe memiliki sebaran lamun yang tersebar di pesisir pantai Teluk Serewe. Namun demikian, berdasarkan tata ruang laut yang telah ditetapkan oleh Pemerintah Prov. NTB di dalam RZWP3K NTB 2017-2037 menyatakan bahwa Perairan Teluk Serewe masuk kedalam pengembangan zona perikanan budidaya dan Ekonomi Biru serta pengembagan budidaya lainnya secara berkelanjutan yang mana pada zona tersebut berpotensi mengancam kelangsungan ekosistem terumbu karang. Selain ancaman yang bersumber dari aktivitas manusia, ancaman juga muncul dari perubahan iklim global yang dapat mengakibatkan pemutihan masal terumbu karang di kawasan Serewe. Pengaruh negatif tersebut secara nyata tampak dari tidak tampaknya klasifikasi terumbu karang di Teluk Serewe dan diperkuat melalui survey lapang yang tidak menemukan adanya zona terumbu karang di Teluk Serewe. Karang hidup ditemukan dengan jumlah yang sangat kecil dan terpisah cukup jauh dari titik karang satu dengan yang lainnya.

\section{Kesimpulan}

Berdasarkan hasil analisa Citra Sentinel 2A diketahui bahwa tidak ditemukan kelas habitat bentik Karang di Teluk Serewe sementara kelas habitat Lamun diketahui tersebar di pesisir yang mengelilingi perairan Di Teluk Serewe dengan luasan mencapai 156 Ha. Selain itu, Kelas habitat campuran dan pasir memiliki luasan berturut-turut yaitu 601.2 Ha dan 337.5 Ha. Tingkat akurasi pengolahan citra sentinel mencapai $63.41 \%$ dengan nilai Kappa sebesar 0.512 .

\section{Ucapan Terima kasih}

Tim penelitian mengucapkan terima kasih kepada KEMENRISTEK/BRIN skema PDP dan LPPM Universitas 45 Mataram, yang telah memfasilitasi kegiatan ini dan juga kepada semua pihak yang telah mendukung pelaksanaan penelitian ini.

\section{Referensi}

Anggoro, A. (2015). Pemetaan Zona Geomorfologi Dan Habitat Bentik Menggunakan Citra Worldview-2 Dengan Metode Obia Di Gugus Pulau Pari. Thesis. Institut Pertanian Bogor.

Hadi, T.A., Giyanto, B. Prayudha, M. Hafizt., \& A. B. Suharsono (2018). Status Terumbu Karang Indonesia 2018. Pusat Penelitian Oseanografi - Lembaga Ilmu Pengetahuan Indonesia. Jakarta.

Hafizt, M, M. D. M. Manessa, N. S. Adi, \& B. Prayudha (2017). Benthic Habitat Mapping by Combining Lyzenga's Optical Model and Relative Water Depth Model in Lintea Island, Southeast Sulawesi IOP Conf. Ser.: Earth Environ. Sci. 98012037

Hafizt, M., \& P. Danoedoro. (2015). Kajian Pengaruh Koreksi Kolom Air pada Citra Multispektral Worldview-2 untuk Pemetaan Habitat Bentik di Pulau Kemujan Kepulauan Karimunjawa Kabupaten Jepara. Dalam C. Ita, M. Setyardi P, S. Ahmad, Y. Dipo, dan Y. Fajar, editors. Kongres VI Mapin 2015. Mapin Jabodetabek, Bogor.

Hafizt, M., Iswari, M. Y., \& Prayudha, B. (2017). Kajian Metode Klasifikasi Citra Landsat-8 untuk Pemetaan Habitat Bentik di Kepulauan Padaido , Papua Assessment of Landsat-8 Classification Method for Benthic Habitat Mapping in Padaido Islands, Papua Abstrak Pendahuluan Metodologi. Oseanologi Dan Limnologi Di Indonesia. (2), 1-13.

Hochberg, E. J., Andrefouet, S., \& Tyler, M. R. (2003). Sea Surface Correction of High Spatial Resolution Ikonos Images to Improve Bottom Mapping in Near Shore Environments. IEEE Trans. Geoscience and Remote Sensing, 41(7), 1724-1729.

Hedley, J. D., Harborne, A. R., \& Mumby, P. J. (2005). Simple and robust removal of sun 
glint for mapping shallowwater benthos. Int. J. of Remote Sensing, 26(10), 2107-2112.

Hedley, J.D., Roelfsema, C.M., Chollett, I., Harborne, A.R., Heron, S.F., Weeks, S., Skirving, W.J., Strong, A.E., Eakin, C.M., Christensen, T.R.L., Ticzon, V., Bejerano, S., \& Mumby, P.J., (2016). Remote sensing of coral reefs for monitoring and management: a review. Remote Sens. (8), $118-157$.

Hedley, J.D., C. Roelfsema, V. Brando, C. Giardino, T. Kutser, S. Phinn, P.J. Mumby, O. Barrilero, J. Laporte, \& B. Koetz. (2018). Coral reef applications of Sentinel-2: Coverage, characteristics, bathymetry and benthic mapping with comparison to Landsat 8. Remote Sensing of Environment (216); 598-614.

Hoegh-Guldberg, O., Mumby, P.J., Hooten, A.J., Steneck, R.S., Greenfield, P., \& Gomez, E., (2007). Coral reefs under rapid climate change and ocean acidification. Science 318 , 1737-1742.

Lewis, H. G. \& M. Brown. (2001). A generalized confusion matrixfor assessing area estimates from remotely sensed data, International Journal of Remote Sensing, 22:16, 32233235, DOI: $10.1080 / 01431160152558332$

Lyzenga D R (1978). Passive remote sensing techniques for mapping water depth and bottom features. Appl. Opt. 17 379-83.

Mumby, P.J., E.P. Green, A.J. Edwards, \& C.D. Clark (1999). The cost-effectiveness of remote sensing for tropical coastal resources assessment and management. Journal of Environmental Management, (55), 157-166.

Pandolfi, J.M., Bradbury, R.H., Sala, E., Hughes, T.P., Bjorndal, K.A., Cooke, R.G., McArdle, D., McClenachan, L., Newman, M.J.H., \& Paredes, G. (2003). Global trajectories of the long-term decline of coral reef ecosystems. Science 301, 955-958. https://doi.org/10.1126/science.1085706.
Prawoto, C. D., \& Hartono (2018). Pemetaan Habitat Bentik dengan Citra Multispektral Sentinel-2a di Perairan Pulau Menjangan Kecil dan Menjangan Besar, Kepulauan Karimunjawa. Jurnal Bumi Indonesia, 7(3), 2-8.

Prayudha, B. (2014). Panduan Teknis Pemetaan Habitat Dasar Perairan Laut Dangkal (Suyarso (Ed.); Issue 1). Coremap CTI LIPI, Jakarta.

Purwanto, A.D., T. Prayoga, \& S. Marpaung (2020). Identification of Coral Reef Using Sentinel 2A Satellite Imagery (Case Study: Coastal Waters of Northern Nias). Jurnal Teknologi Lingkungan (21); 095-108.

Sari, C. A., A. F. Syah, B. Prayudha, \& A. Salatalohi (2020). Pemetaan Habitat Bentik Menggunakan Citra Satelit Sentinel-2a Di Pulau Liki, Papua. Jurnal Penginderaan Jauh dan Pengolahan Data Citra Digital, 17 (1).

UNEP. (1988). Coral reefs of the world. vol. 2: Indian Ocean, Red Sea and Gulf. UNEP Regional Seas Directories and Bibliographies. IUCN, Gland, Switzerland and Cambridge, UK. UNEP, Nairobi, Kenya. 1988. 389pp.

Zhang, C., Selch, D., Xie, Z., Roberts, C., Cooper, H., \& Chen, G. (2013). Object-based benthic habitat mapping in the Florida Keys from hyperspectral imagery. Estuarine, Coastal and Shelf Science, 134(June 2018), 88-97. https://doi.org/10.1016/j.ecss.2013.09.018 